\title{
EDITORIAL
}

\section{A snapshot of research in learning technology}

The papers in this issue present a convenient snapshot of current research in learning technology, both in their coverage of the issues that concern us and the methods that are being used to investigate them. This issue shows that e-learning researchers are interested in: what technologies are available and explorations of their potential (Nie et al. explore the role of podcasting), how to design technology-mediated learning activities in ways which support specific learning outcomes (Simpson evaluates the role of 'book raps' in supporting critical thinking), the identification of critical success factors in implementations (Cochrane's observation of three mobile learning projects) and how such e-learning initiatives can be sustained within an institutional context (Gunn's examination of the challenges of embedding 'grass roots' initiatives). Finally e-learning research is concerned with investigating the impact of emerging technologies on education - in this case Traxler's discussion of mobile, largely student-owned, devices. Together these five papers demonstrate the scope of research in learning technology and it is with this in mind that we will soon be referring to this journal by its subtitle: Research in Learning Technology.

Cathy Gunn begins our journey into learning technology research with a study of how e-learning practices have been sustained in such as way as to be transformational to institutional practice. Having identified a number of individual e-learning champions in the higher education sector in New Zealand, she interviewed a selection of practitioners, managers and support staff, to find out what they thought had contributed to the sustainability of their initiatives. Gunn confirms that a shared vision is important, as are supportive institutional structures. Drawing comparisons between product development in research and business settings, Gunn suggests that institutions need to consider not just how they support innovation and development, but also the dissemination and adoption of the outputs of that development. With her focus on sustaining 'grass roots' initiatives, Gunn proposes that such an approach should be based on principles of collective action and cross functional collaboration.

Ming Nie and colleagues also examine transformational practice, although this time from a course design perspective. In this paper, a team of developers works alongside a course team to assess the role of a specific technology in transforming the curriculum. This study goes beyond previously documented student ratings of podcasting to attempt to specify what the benefits of podcasting might be in the curriculum. A number of benefits are identified which are important within the context of this particular distance learning course. These include the role of the human voice in reducing perceptions of isolation, the value of audio in giving advice, support and guidance, and the increased flexibility and mobility in time and place of study. They show that students use podcasts in various ways, some listening to them on computers and some playing the podcasts on mobile devices. A further benefit for course teams is the ability to 'design once, deliver many times' with minimum adaptation. Nie et al. 
comment on the importance of sharing this example of researched curriculum change in promoting change in other parts of their institution. It is worth remembering the value of such published research, both to the development of the field and to those making changes on the ground.

Where Nie et al. are quite open in their investigation of what the impact of podcasts might be, Simpson's investigation has specific outcomes in mind. Alyson Simpson assesses the expected impact of the technology-supported 'book raps' on the development of critical thinking in primary school children. The focus here is on the design of the learning activities rather than the technology (email) - which is well established. Like much use of technology in practice, it takes place in blended context. Many elements of the blended context are seen to be important: the choice of books for the rap, the classroom teacher's skills in scaffolding critical discussion, and the online moderator's pedagogic design. This study exemplifies the reality of much technology-based learning - where there is just a dash of technology integrated into existing practice. Here the aim is not transformation, but the teachers wanting to 'enrich' their usual practices. Indeed, the learners did not directly interact with the technology at all. Rather it was the pedagogic structure of bringing together learners' individual and group thoughts to be posted publicly online, and reading the contributions from other schools, which was sufficient to make a difference to their learning and progression.

There are two papers about mobile learning in this issue, continuing to demonstrate the level of interest in this topic we found in the recent special issue on mobile and contextual learning (Volume 17, Number 3). First, Thomas Cochrane reviews how mobile technology was used in three different course contexts. Cochrane attempts to synthesize the common critical success factors in these case studies. The findings seem familiar now: integrating the technology into the pedagogic design of the course, the course tutor modeling appropriate use of the tools, the importance of students receiving regular formative feedback and the appropriate choice of technology to fit the pedagogic model. The fact that these critical success factors recur frequently illustrates how far we have come as a field of research. In the second paper on mobile learning, John Traxler encourages us to think creatively about where these, and other disruptive technologies, might be taking us in the future.

Traxler's paper discusses the challenges and opportunities for education of the wide-scale student ownership of mobile technology. He observes the social trends in ownership, availability and functionality of mobile technology and contemplates the possible implications for universities if they are to take advantage of these changes. Despite the current enthusiasm for using mobile technology, Traxler presents us with something of a reality check. He reminds us that the mobile technologies we seem so enthusiastic about are "poorly suited to learning, will all be different and will all be changing, often for reasons that are not technical, not educational and probably not even rational or foreseeable". How then, are we supposed to make use of these for learning? For Traxler, the potential of mobile technology is the fact that it is commonplace and accessible. He believes that the ways students use technology in their everyday lives will mean that they will feel "less inhibited and less intimidated" by the technology which forms part of their learning experience. The disruptive influence of such pervasive, personal technology, Traxler argues, is "to challenge the authority of the curriculum and the institutions of formal learning". We must work out how to unlock the potential of student devices for learning (if there is one) without putting equity, access and participation at risk. The question then is how the knowledge 
gained from our previous investigations of learning technology can help us to understand the potential of mobile technology. We have seen in this issue alone that much of the research in this field derives from institutional, curriculum and course based evaluations. How can these help us understand the technology we will be faced with in the future? It is clear that research of learning that takes place outside of formal educational contexts is going to become increasingly important.

This collection of papers is a snapshot of learning technology research in terms of both the issues being studied and the ways in which they are being investigated. Represented here are: empirical research with students as subjects, analysis of reflections from practitioners, synthesis of projects in context and thought provoking critiques. All of these types of studies and papers are welcome in this journal. A call for us to research, publish and share what we know seems particularly appropriate at the time of writing, as the closure of Becta is announced. Becta is a UK government agency for supporting the use of ICT in schools and colleges. It has built up an international reputation for its research programmes and guidance materials. It is being closed as part of a decentralization agenda to place choices about technologies and their use into the hands of schools, colleges and teachers. For e-learning researchers, this is a reminder of the need to keep publishing and disseminating our work in ways which can help to inform the choices teachers everywhere must make every day.

Rhona Sharpe

Oxford Brookes University, UK 